\title{
Consequences of a sortase A mutation in Streptococcus gordonii
}

\author{
Angela H. Nobbs, ${ }^{1} \dagger \ddagger$ Reka M. Vajna, ${ }^{1} \dagger$ Jeremy R. Johnson, ${ }^{1}$ \\ Yongshu Zhang, ${ }^{1}$ Stanley L. Erlandsen, ${ }^{2}$ Monika W. Oli, ${ }^{3}$ Jens Kreth, ${ }^{1}$ \\ L. Jeannine Brady ${ }^{3}$ and Mark C. Herzberg ${ }^{1,4}$ \\ ${ }^{1}$ Department of Diagnostic and Biological Sciences, School of Dentistry, Medical School, \\ University of Minnesota, Minneapolis, MN 55455, USA \\ ${ }^{2}$ Department of Genetics, Cell Biology and Development, Medical School, University of Minnesota, \\ Minneapolis, MN 55455, USA \\ ${ }^{3}$ Department of Oral Biology, Joint Health Science Center, University of Florida, Gainesville, \\ FL 32611, USA \\ ${ }^{4}$ Mucosal and Vaccine Research Center, Minneapolis VA Medical Center, Minneapolis, \\ MN 55417, USA
}

Correspondence

Mark C. Herzberg mcherzb@umn.edu

Received 30 April 2007

Revised 27 July 2007

Accepted 28 August 2007
Sortase A (SrtA) is required for cell-wall anchoring of LPXTG-containing Gram-positive surface proteins. It was hypothesized, therefore, that disruption of the srtA gene would alter surface anchoring and functions of target LPXTG motif-bearing SspA and SspB proteins of Streptococcus gordonii. Mutant strains in srtA (V288srt $A^{-}$, DL1 srt $\left.A^{-}\right)$were constructed in $S$. gordonii V288 (wtV288) and DL1 (wtDL1). When compared to wtV288, the V288srtA- mutant showed decreased biofilm formation on polystyrene, and reduced binding to immobilized purified salivary agglutinin (BIAcore analysis). The wtV288 and V288srt $A^{-}$strains were similar in ultrastructure, but immunogold-labelled SspA/SspB surface expression was reduced on the V288srt $A^{-}$mutant. DL1srt $A^{-}$was also complemented to obtain DL1srt $A^{+}$. From the wild-type strains (wtV288, wtDL1), srt $A^{-}$mutants (V288srt $A^{-}, \mathrm{DL} 1 \mathrm{srt} A^{-}$), and the complemented mutant $\left(\mathrm{DL} 1 s r t A^{+}\right)$, cytoplasmic, cell-wall and released extracellular protein fractions were isolated. Each fraction was analysed by SDS-PAGE and immunoblotting with anti-P1. Spent medium from srt $A^{-}$ mutant cells contained over-represented proteins, including SspA/SspB (P1 antigen). Mutants showed less $\mathrm{P} 1$ on the cell surface than wild-types, as estimated using whole-cell ELISA, and no $\mathrm{P} 1$ appeared in the cytoplasmic fractions. Expression of several adhesin genes $(\operatorname{ssp} A / B, \operatorname{csh} A / B$, $f b p A)$ was generally upregulated in the mutants $\left(\mathrm{V} 288 s r t A^{-}, \mathrm{DL} 1 \mathrm{srt} A^{-}\right)$, but restored to wild-type levels in DL1srt $A^{+}$. These data therefore imply that in addition to its role in processing LPXTGcontaining adhesins, sortase $A$ has the novel function of contributing to transcriptional regulation of adhesin gene expression.

\section{INTRODUCTION}

Streptococcus gordonii is a non-cariogenic pioneer colonizer of the tooth surface in the oral cavity (Kuboniwa et al., 2006; Schachtele et al., 2007). Following entry into the

†These authors contributed equally to this work.

$\ddagger$ Present address: Novartis Vaccines, Centro Ricerche, Via Fiorentina 1, 53100 Siena, Italy.

Abbreviations: DL1srtA ${ }^{-}$, sortase A negative mutant in Streptococcus gordonii DL1 wild-type; DL1srtA ${ }^{+}$, complemented DL1srtA ${ }^{-}$; P1, antigen class $I / I I$ surface protein of Streptococcus mutans; RU, resonance units; V288srtA ${ }^{-}$, sortase A negative mutant in $S$. gordonii V288 wild-type; wtDL1, S. gordonii DL1 wild-type; wtV288, S. gordonii V288 wild-type. blood, S. gordonii can be isolated from prosthetic heart valves and is a frequent cause of infective endocarditis (Douglas et al., 1993; Sommer et al., 1992). The ability of this species to adhere is essential for survival in all known environments. Among the LPXTG-motif-containing surface proteins, SspA/B, CshA/B and Hsa are expressed by $S$. gordonii and are essential for adhesion and colonization (Demuth et al., 1996; Holmes et al., 1998; Jakubovics et al., 2005; McNab \& Jenkinson, 1998). S. gordonii also utilizes non-LPXTG adhesins, including ScaA, AbpA, AbpB and FbpA (Schachtele et al., 2007). Expressed in S. gordonii and virtually all Gram-positive bacteria (Mazmanian et al., 2002; Scott et al., 2002), sortase A (SrtA) is a membranelocalized transpeptidase that specifically cleaves the LPXTG 
sequence, and transfers the processed exported $\mathrm{N}$-terminal polypeptide to peptidoglycan, where it covalently crosslinks to the cell wall (Paterson \& Mitchell, 2004).

Sortase A is responsible for the anchoring of LPXTGcontaining surface proteins to the cell wall (Paterson \& Mitchell, 2004). In Staphylococcus aureus, a mutation in the $s r t A$ gene results in defective anchoring of several proteins, including a number of surface-associated adherence factors (Mazmanian et al., 1999). In Streptococcus mutans biofilms in vitro, genes encoding three putative sortase A-dependent proteins are upregulated when compared to planktonic cells, and mutations in srtA reduce biofilm biomass (Levesque et al., 2005). Consistent with sortase A anchoring of specific adhesive proteins, a recombinant M6 protein of Streptococcus pyogenes containing the LPXTG motif was expressed in S. gordonii GP1223 (Bolken et al., 2001). An isogenic srtA knockout expressed markedly less surface M6 protein and showed reduced binding to immobilized human fibronectin and oral colonization of mice.

The LPXTG surface proteins of $S$. gordonii can be modelled by SspA and SspB (El-Sabaeny et al., 2000; Holmes et al., 1998; Williams et al., 1994). SspA and SspB are members of the antigen I/II family of proteins ( $70 \%$ sequence identity), which are expressed by virtually all species of oral streptococci (Demuth et al., 1997). SspA and SspB contain a specific 35-residue C-terminal sorting signal, consisting of an LPXTG sequence motif and hydrophobic and positively charged domains (Fischetti et al., 1990; Schneewind et al., 1992, 1993).

To show how sortase A affects the distribution and function of an endogenous adhesin, we tested the hypothesis that disruption of the srtA gene in $S$. gordonii changes the localization of SspA and SspB adhesins, biofilm formation, and binding to a specific salivary agglutinin receptor in vitro. Since $S$. gordonii must adhere to salivacoated teeth to survive and avoid extinction, we noted that while the $s r t A^{-}$mutants showed loss of function, the organism appeared to adapt to the abnormalities in expression of the LPXTG adhesins. Since we have reported (Zhang et al., 2005) that mutations in S. gordonii SspA and SspB caused upregulation of other adhesin genes to complement loss of adhesion function, we also explored if sortase A might regulate compensating expression of adhesin genes.

\section{METHODS}

Bacterial strains and culture conditions. Streptococci (listed in Table 1) were routinely grown in chemically defined synthetic media (FMC) (Terleckyj et al., 1975) for $16-20 \mathrm{~h}$ at $37{ }^{\circ} \mathrm{C}$ in $5 \% \mathrm{CO}_{2}$. Escherichia coli DH5 $\alpha$ cells were grown aerobically at $37{ }^{\circ} \mathrm{C}$ in LuriaBertani (LB) medium. When required, antibiotics were added to the medium at the following concentrations: erythromycin (Em), $5 \mu \mathrm{g} \mathrm{ml}^{-1}$ (DL1srtA $\left.A^{-} / \mathrm{V} 288 s r t A^{-}\right) ; \operatorname{kanamycin}(\mathrm{Km}), 50 \mu \mathrm{g} \mathrm{ml}^{-1}$ (E. coli) or $250 \mu \mathrm{g} \mathrm{ml}^{-1}\left(\mathrm{DL} 1\right.$ srtA $\left.^{+}\right)$.

Genetic manipulations in S. gordonii V288 and DL1. Standard recombinant DNA techniques were employed as described (Sambrook et al., 1989). Plasmids (listed in Table 1) were purified from E. coli cells using the QIAquick Spin Miniprep Purification Kit (Qiagen). Oligonucleotides were synthesized by Integrated DNA Technologies (listed in Table 2).

Chromosomal DNA was prepared from mutanolysin-treated streptococcal cells using the Qiagen 100/G Genomic Tip System. PCR products were purified using the High Pure PCR Product Purification Kit (Roche). DNA restriction and modification enzymes were used under the conditions specified by the manufacturer (Promega).

Table 1. Bacterial strains and plasmids used in this study

\begin{tabular}{|c|c|c|}
\hline Strain/plasmid & Relevant characteristics & Source/reference \\
\hline \multicolumn{3}{|l|}{ E. coli } \\
\hline DH5 $\alpha$ & $\begin{array}{l}\mathrm{F}^{-} \phi 80 \mathrm{~d} l a c Z \Delta \mathrm{M} 15 \Delta(\text { lacZYA-argF }) \mathrm{U} 169 \text { recA1 } \\
\text { endA1 hsdR17 }\left(\mathrm{r}_{\mathrm{k}}^{-} \mathrm{m}_{\mathrm{k}}^{-}\right) \text {phoA supE44 } \lambda^{-} \text {thi-1 } \\
\text { gyrA96 relA1 }\end{array}$ & Invitrogen \\
\hline \multicolumn{3}{|c|}{ or } \\
\hline DL1 (Challis) & Wild-type & Pakula \& Walczak (1963) \\
\hline DL1srtA $A^{-}$ & $\Delta($ srtA $):: \operatorname{erm} A M$ & This study \\
\hline DLIsrt $^{+}$ & $\Delta($ srtA $)::$ ermAM complemented with pDL276-srtA & This study \\
\hline V288 & Wild-type & G. Dunny, Univ. Minnesota \\
\hline $\mathrm{V} 288 s r t A^{-}$ & srtA:: ermAM & This study \\
\hline \multicolumn{3}{|l|}{ Plasmids } \\
\hline pGEM-T Easy & $3.0 \mathrm{~kb} ; \mathrm{Ap}^{\mathrm{R}} ;$ ColE1ori & Promega \\
\hline pGEM-srtA.ermAM & $\begin{array}{l}\text { pGEM-T Easy derived containing ermAM cassette } \\
\text { within flanking sequences of srtA gene }\end{array}$ & This study \\
\hline pVA891 & $\begin{array}{l}5.4 \mathrm{~kb} ; \mathrm{Em}^{\mathrm{R}}, \mathrm{Cm}^{\mathrm{R}} ; \mathrm{pACYCori} \text { E. coli-streptococcal } \\
\text { shuttle vector }\end{array}$ & Macrina et al. (1983) \\
\hline pDL276 & $\begin{array}{l}6.9 \mathrm{~kb} ; \mathrm{Km}^{\mathrm{R}} \text {; ColE1 ori; E. coli-streptococcal shuttle } \\
\text { vector }\end{array}$ & Dunny et al. (1991) \\
\hline pDL276-srtA & pDL276 derived containing entire srtA gene & This study \\
\hline
\end{tabular}


Table 2. Primers used in this study

\begin{tabular}{|c|c|}
\hline Primer $^{*}$ & Sequence $\dagger$ \\
\hline srtA.F1 & CGGGGTACCCATGGCCTGTAGCTCAATC \\
\hline srtA.F2 & CCATCGATCCTTCTCGTCTTGCAACTC \\
\hline srtA.R1 & GGATCGATGGAAGGAAGCATAAGTTTAATGC \\
\hline srtA.R2 & CGCGAGCTCACCTAAGAGACGGTGACCAG \\
\hline ermAM.F & CCATCGATGGCCATATCATAAAAATCGAAACAGO \\
\hline ermAM.R & CCATCGATGGTAGGGACCTCTTTAGCTCC \\
\hline RealsrtA.F & ATGGAAAGCACAGCAACTTC \\
\hline RealsrtA.R & CTGTAATCCCGAAAACATGG \\
\hline fbpA.F & GCTCAAAGAAGCCGTCAAAC \\
\hline fbpA.R & GTTGCGGCCAACTAGGATAA \\
\hline
\end{tabular}

${ }^{*}$ All primers were designed as part of this study.

$\dagger$ Underlined letters indicate restriction enzyme site.

The V288srtA $A^{-}$mutant was constructed in $\mathrm{wtV} 288$ by insertion duplication using the pCR2.1:B210 plasmid (a gift from Sigma) (Bolken et al., 2001). The mutant was selected for resistance to $5 \mu \mathrm{g}$ erythromycin $\mathrm{ml}^{-1}$ and confirmed by PCR as described previously (Bolken et al., 2001). Unfortunately, attempts to complement the $s r t A^{-}$mutation in strain V288 were unsuccessful. Thus, the closely related strain, DL1 (Challis), was used for this purpose.

The srtA gene of $S$. gordonii DL1 was inactivated by allelic exchange with the erythromycin resistance determinant, ermAM. PCR amplification with primers (Table 2) srtA.F1/srtA.R1 and srtA.F2/srtA.R2 of S. gordonii DL1 chromosomal DNA template generated two fragments comprising the flanking sequences of the $s r t A$ gene (324 bp, $381 \mathrm{bp}$ ), which were ligated via a unique $\mathrm{ClaI}$ site and cloned into pGEM-T Easy. A DNA fragment $(1023 \mathrm{bp})$ containing the ermAM gene was PCR-amplified from plasmid pVA891 using primers ermAM.F/ermAM.R that incorporated ClaI restriction sites. The PCR product was digested with $\mathrm{ClaI}$ and ligated into the unique site within the combined srtA fragments, generating plasmid pGEMsrtA.ermAM. The insert DNA from this plasmid was PCR-amplified using primers srtA.F1/srtA.R2, purified and transformed into $S$. gordonii DL1, thus generating the srtA deletion mutant, DL1srtA ${ }^{-}$. Confirmation of predicted insertions was obtained by PCR amplification and sequencing.

To complement the DL1srtA ${ }^{-}$mutant, a DNA fragment (1484 bp) incorporating the entire srtA gene was PCR-amplified from $S$. gordonii DL1 chromosomal DNA using primers srtA.F1/srtA.R2. The PCR product was cloned into $E$. coli-streptococcal shuttle vector pDL276, generating plasmid pDL276-srtA. This construct was purified and used to transform the DL1srt $A^{-}$mutant. Confirmation of predicted insertions was obtained by PCR amplification and sequencing. Complementation was confirmed by detection of srtA RNA transcript using primers RealsrtA.F/RealsrtA.R (data not shown). RNA extraction and cDNA synthesis were performed as described below.

No significant difference was found in the growth of any of the mutants compared to their respective wild-type strains (data not shown).

Biofilm formation assay. As reported previously (Loo et al., 2000), bacteria were grown in 96 -well plastic plates at $37{ }^{\circ} \mathrm{C}$ for $16-18 \mathrm{~h}$. The biomass was then stained with $25 \mu \mathrm{l}$ of $1 \%(\mathrm{w} / \mathrm{v})$ crystal violet for $15 \mathrm{~min}$ and washed to remove planktonic cells and unincorporated stain. To estimate sessile biomass, $250 \mu \mathrm{l}$ of $70 \%$ ethanol was added to each well. From each well, $125 \mu$ of the extracted crystal violet was transferred to a new well in a polystyrene microtitre plate and the absorbance at $568 \mathrm{~nm}$ was determined with an ELISA reader.

Preparation of salivary agglutinin. Salivary agglutinin was prepared by a modification of a technique reported previously (Rundegren \& Arnold, 1987). Unstimulated saliva was collected on ice from healthy volunteers and clarified by centrifugation at $8000 \mathrm{~g}$ for $20 \mathrm{~min}$ at $4{ }^{\circ} \mathrm{C}$. Agglutinin was prepared by adsorption of the clarified saliva with S. mutans as described previously (Brady et al., 1992). Equal volumes of clarified saliva, phosphate-buffered saline (PBS; $2.7 \mathrm{mM} \mathrm{KCl}, 1.5 \mathrm{mM} \mathrm{KH_{2 }} \mathrm{PO}_{4}, 137 \mathrm{mM} \mathrm{NaCl}, 6.5 \mathrm{mM}$ $\mathrm{Na}_{2} \mathrm{HPO}_{4}, \mathrm{pH}$ 7.2) and PBS-washed S. mutans NG8 cells (Klett reading of 600) were mixed and incubated on a rotor at $37^{\circ} \mathrm{C}$ for $30 \mathrm{~min}$. Cells with adherent agglutinin were removed from the saliva by centrifugation at $2000 \mathrm{~g}$ for $15 \mathrm{~min}$ and washed once with PBS. Adsorbed agglutinin was eluted from the cells with one volume of PBS containing $1 \mathrm{mM}$ EDTA. Cells were removed by centrifugation $(4000 \mathrm{~g}, 20 \mathrm{~min})$ and the agglutinin preparation was filter-sterilized with a $0.2 \mu \mathrm{m}$ acrodisc filter (Pall), dialysed against PBS to remove EDTA, and stored in aliquots at $-20{ }^{\circ} \mathrm{C}$. Total protein concentration was determined by the bicinchoninic acid (BCA) protein assay (Pierce) and adjusted to $100 \mathrm{ng} \mathrm{ml}^{-1}$.

Binding to salivary agglutinin. The interaction of $S$. gordonii with immobilized agglutinin was analysed using the BIAcore 3000 machine with a Pioneer F1 sensor chip, as described by Oli et al. (2006). Salivary agglutinin, isolated as described above, was covalently bound to the activated carboxyl groups of the dextran molecules in the flow cell (FC) 2 . The dextran matrix was activated with $35 \mu$ of an equal mixture of $N$-hydrosuccinimide $\left(115 \mathrm{mg} \mathrm{ml}^{-1}\right)$ and $N$-ethyl- $N^{\prime}$ (dimethylaminopropyl)carbodiimide $\left(750 \mathrm{mg} \mathrm{ml}^{-1}\right.$ ), as suggested by the manufacturer. Agglutinin $\left(100 \mathrm{ng} \mathrm{ml}^{-1}\right)$ was diluted $1: 5(\mathrm{v} / \mathrm{v})$ in $10 \mathrm{mM}$ sodium acetate buffer $(\mathrm{pH} \mathrm{5)}$ and $2-3 \times 20 \mu \mathrm{l}$ was injected manually until the change in resonance units (RU) was $\sim 1500$, indicating the immobilization of $1.5 \mathrm{ng}$ protein. The remaining activated dextran was inactivated by injection of $2 \times 35 \mu \mathrm{l}$ of $1 \mathrm{M}$ ethanolamine. All experiments were conducted at $25{ }^{\circ} \mathrm{C}$ in modified adhesion buffer $\left(0.78 \mathrm{mM} \mathrm{KH_{2 }} \mathrm{PO}_{4}, 1.22 \mathrm{mM} \mathrm{K} \mathrm{K}_{2} \mathrm{HPO}_{4}, 50 \mathrm{mM}\right.$ $\mathrm{KCl}, 1 \mathrm{mM} \mathrm{CaCl}_{2} \cdot 6 \mathrm{H}_{2} \mathrm{O}, \mathrm{pH}$ 7.2) (Clark et al., 1978) and the flow rate was maintained at $10 \mu \mathrm{min}^{-1}$ throughout. To serve as a reference surface, FC 1 was treated in the same way, but agglutinin was omitted.

To determine the binding of cells of $S$. gordonii to purified salivary agglutinin, wtV288 and V288srtA ${ }^{-}$mutant were grown in $10 \mathrm{ml}$ cultures for $16 \mathrm{~h}$ at $37{ }^{\circ} \mathrm{C}$ in Todd-Hewitt broth (BBL) supplemented with $0.3 \%(\mathrm{w} / \mathrm{v})$ yeast extract, and with $5 \mu \mathrm{g}$ erythromycin $\mathrm{ml}^{-1}$ for V288srt $A^{-}$. Cells were harvested by centrifugation and washed once in modified adhesion buffer. After resuspending cells in modified adhesion buffer to $\sim 1 \times 10^{10}$ c.f.u. $\mathrm{ml}^{-1}(5 \mathrm{ml})$, the bacterial suspension was sonicated for $30 \mathrm{~s}$ to disrupt chains and form a single-cell suspension (Sonic Dismembrator, model 100, Fisher Scientific, setting 5) and washed again. Cells were then resuspended in $5 \mathrm{ml}$ modified adhesion buffer and diluted 1:10 before use.

S. gordonii cells $\left(\sim 1 \times 10^{9}\right.$ c.f.u. $\left.\mathrm{ml}^{-1}\right)$ in modified adhesion buffer were injected at a flow rate of $10 \mu \mathrm{lmin}^{-1}$ for $60 \mathrm{~s}$, totalling approx. $1 \times 10^{7}$ c.f.u. per injection. Adherent bacterial cells were removed by injection of $10 \mu \mathrm{l}$ regeneration solution [PBS- $0.3 \%$ (v/v) Tween-20 with $10 \mathrm{mM} \mathrm{Na} 2$ EDTA, $100 \mathrm{mM} \mathrm{NaCl}$ and $100 \mathrm{mM} \mathrm{NaOH}$, which allowed repeated reuse of the sensor chip surface. S. mutans NG8 cells were analysed for binding as a positive control. Binding of cells to the sensor chip surface was monitored by the change in refractive index over time with resonance signal (RU) plotted on the $y$-axis and time on the $x$-axis.

Fractionation of S. gordonii cells. Cells were fractionated by a modifiction of our previously reported method (Herzberg et al., 
1990). Overnight bacterial cultures $(100 \mathrm{ml})$ in FMC were harvested $(3000 \mathrm{~g}, 20 \mathrm{~min})$ and the supernatant and cell pellet collected separately. Supernatants were dialysed against $0.2 \% \quad(\mathrm{w} / \mathrm{v})$ $\mathrm{Na}_{2}$ EDTA, followed by distilled water, concentrated by lyophilization, and designated the extracellular fraction. Cell pellets were resuspended in $10 \mathrm{ml}$ spheroplasting buffer $(20 \mathrm{mM}$ Tris/ $\mathrm{HCl} \mathrm{pH} 6.8$, $10 \mathrm{mM} \mathrm{MgCl}_{2}, 26 \%$ (w/v) raffinose), and mutanolysin (Sigma) was added at a final concentration of $80 \mathrm{U} \mathrm{ml}^{-1}$. After incubation at $37{ }^{\circ} \mathrm{C}$ for $1 \mathrm{~h}$, suspensions were chilled on ice, and the protoplasts and supernatants then separated by centrifugation $(12000 \mathrm{~g}, 20 \mathrm{~min}$, $\left.4{ }^{\circ} \mathrm{C}\right)$. Supernatants were collected, dialysed, concentrated by lyophilization and designated the cell-wall fraction. Protoplasts were resuspended in $10 \mathrm{ml}$ of $50 \mathrm{mM}$ triethanolamine $/ 250 \mathrm{mM}$ sucrose, lysed by sonication $(50 \mathrm{~W}, 8 \mathrm{~min})$, and insoluble materials were removed by centrifugation $\left(12000 \mathrm{~g}, 20 \mathrm{~min}, 4{ }^{\circ} \mathrm{C}\right)$. Supernatants were collected, dialysed, concentrated by lyophilization and designated the cytoplasmic fraction. Protein concentrations for each fraction were determined using BCA Protein Assay (Pierce). To compare protein profiles, each fraction ( $20 \mu \mathrm{g}$ protein) was resolved by $8 \%(\mathrm{w} / \mathrm{v})$ SDS-PAGE and stained with Coomassie blue.

Western immunoblotting. Proteins were extracted from S. gordonii strains and resolved on $8 \%(\mathrm{w} / \mathrm{v})$ SDS-PAGE gels, as described above. Proteins were transferred onto Trans-Blot nitrocellulose membrane (Bio-Rad) at $15 \mathrm{~V}$ for $30 \mathrm{~min}$ using a Trans-Blot SD Semi-Dry Electrophoretic Transfer Cell (Bio-Rad). Membranes were then probed with rabbit anti-S. mutans P1 serum (1:1000 dilution) (gift of Neil Hunter, Millenium Institute of Dental Research, Westmead and Sydney, Australia), and the results visualized with goat anti-rabbit alkaline phosphatase-conjugated IgG (Bio-Rad) and 5-bromo-4chloro-3-indolylphosphate (BCIP)-Nitro Blue Tetrazolium (Sigma) (Brady et al., 1998; Lee \& Boran, 2003). As reported previously, the rabbit anti-S. mutans $\mathrm{P} 1$ antibodies (Forester et al., 1983) specifically recognize SspA and SspB of S. gordonii (Heddle et al., 2003; Holmes et al., 1998; Jakubovics et al., 2005).

Immunogold labelling. Bacteria were grown overnight in FMC medium at $37{ }^{\circ} \mathrm{C}$ and diluted to $\mathrm{OD}_{620} 0.3$. Bacterial cultures $(1 \mathrm{ml})$ were pelleted by centrifugation, washed with PBS, resuspended in PBS containing $5 \%(\mathrm{v} / \mathrm{v})$ goat serum, and incubated with a $20 \mu \mathrm{g} \mathrm{ml}^{-1}$ solution of rabbit anti-P1 antibody for $2 \mathrm{~h}$. At $2 \mathrm{~h}$, bacteria were washed three times with PBS-5\% (v/v) goat serum, incubated for $1 \mathrm{~h}$ with goat anti-rabbit immunoglobulin conjugated to $10 \mathrm{~nm}$ diameter colloidal gold particles (Sigma) diluted 1:50, and then washed three times with PBS. The bacteria were examined by backscatter electron imaging using a Hitachi S-900 field emission scanning microscope ( $5 \mathrm{keV}$ ), as described previously (Olmsted et al., 1993). For quantification, gold particles were counted on 30 randomly selected $\mathrm{wtV} 288$ and $\mathrm{V} 288$ srt $A^{-}$bacterial cells, the identities of which were blinded from the observer.

Whole-cell ELISA. Overnight cultures $(3 \mathrm{ml})$ of $S$. gordonii strains were harvested, washed and immobilized in the wells $\left(4 \times 10^{8}\right.$ cells per well) of 96-well Maxisorp microtitre plates (Nunc), as described previously (Holmes et al., 1995). The wells were then incubated with $0.1 \mathrm{ml}$ blocking buffer [10 mM Tris/ $\mathrm{HCl} \mathrm{pH} 8.0,0.15 \mathrm{M} \mathrm{NaCl}, 0.1 \%$ $(\mathrm{v} / \mathrm{v})$ Tween-20, $2.5 \%(\mathrm{w} / \mathrm{v}) \mathrm{BSA}]$ for $16 \mathrm{~h}$ at $4{ }^{\circ} \mathrm{C}$. Next, $50 \mu \mathrm{l}$ of a $1: 25$ dilution of rabbit anti-P1 antibody in blocking buffer was added to each well and plates were incubated for $2.5 \mathrm{~h}$ at room temperature. After three washes with TBST buffer $[10 \mathrm{mM}$ Tris/ $\mathrm{HCl} \mathrm{pH} 8.0$, $0.15 \mathrm{M} \mathrm{NaCl}, 0.1 \%$ (v/v) Tween-20], $50 \mu \mathrm{l}$ of a $1: 125$ dilution of goat anti-rabbit IgG antibody conjugated with horseradish peroxidase (Santa Cruz Biotechnology) in blocking buffer was added to each well. After $2.5 \mathrm{~h}$ incubation at room temperature, bound antibody was detected using the Stable Peroxide Substrate Buffer (Pierce), following the manufacturer's instructions.
RNA extraction and cDNA synthesis. RNA extraction from bacterial cultures, confirmation of RNA integrity and purity on agarose gels, and cDNA synthesis were performed as described previously (Zhang et al., 2004, 2005). For each RNA sample, a control cDNA reaction in the absence of reverse transcriptase was performed to check for DNA contamination.

Real-time PCR. Real-time quantitative PCR was modified from the method of Zhang et al. (2005) using the Mx3000 Real-Time PCR System (Stratagene). PCR reactions $(25 \mu \mathrm{l})$ comprised $12.5 \mu \mathrm{l} 2 \times$ Brilliant SYBR Green QPCR Master Mix (Stratagene), 50 pmol each forward and reverse primer and $3 \mu$ template. The 16S rRNA gene was used as the endogenous reference control, and real-time PCR results were quantified based on standard curves, as described previously (Zhang et al., 2005). The primer set used to amplify the $f b p A$ gene is given in Table 2, whilst the primer sets used for $s s p A$, $\operatorname{ssp} B, s c a A, a b p A, a b p B, h s a, c s h A, c s h B$ and $16 \mathrm{~S}$ rRNA were as described previously (Zhang et al., 2005).

Statistics. S. gordonii strains were compared for differences in gene expression levels and cell-surface P1 antigen using the Student's $t$-test.

\section{RESULTS}

\section{Functional effects}

Biofilm assay. Biofilm formation was assessed by release of crystal violet from the biomass that had formed on plastic. The V288srtA $A^{-}$mutant showed a significant decrease $(35 \%, P=0.002, n=8)$ in biofilm formation ability when compared to the wild-type (Fig. 1a).

Binding to salivary agglutinin. To investigate the role of sortase A in controlling adhesin surface expression, we determined binding of wtV288 and V288srtA ${ }^{-}$mutant cells to salivary agglutinin in a BIAcore flow cell assay (Fig. 1b). Salivary agglutinin is the specific receptor on saliva-coated hydroxyapatite for the antigen I/II family of adhesins (Demuth \& Irvine, 2002) and for Hsa (Jakubovics et al., 2005; Nobbs et al., 2007). The wtV288 cells bound rapidly to the sensor chip coated with salivary agglutinin. The wtV288 binding curve (sensogram) reflected a change in refractive index $(\triangle \mathrm{RU})$ of 206 during the first $60 \mathrm{~s}$, significantly faster than the V288srtA $A^{-}$mutant $(\Delta \mathrm{RU}=3)$. Overall binding of the V288srtA $A^{-}$mutant was reduced by $97 \%$. Similarly, wtDL1 showed a $60 \mathrm{~s} \Delta \mathrm{RU}=184$. These data were then compared against those of $S$. mutans, for which the antigen I/II adhesin, SpaP, has been shown to mediate binding to salivary agglutinin (Oli et al., 2006). S. mutans NG8 (wildtype) was used as a positive control and the salivary agglutinin-binding negative $S$. mutans PC3370 spaP (isogenic) mutant (Oli et al., 2006) was used as a negative control and these were analysed under identical conditions. Like the V288srtA $A^{-}$mutant, the mutation in the adhesin spaP gene resulted in loss of $S$. mutans binding to salivary agglutinin. When the sensor was prepared without agglutinin, overall binding of bacterial cells was $90 \%$ less (data not shown). Hence, srtA is required for functional expression of an S. gordonii adhesin(s) for salivary agglutinin with a binding profile similar to SpaP of S. mutans. 
(b)

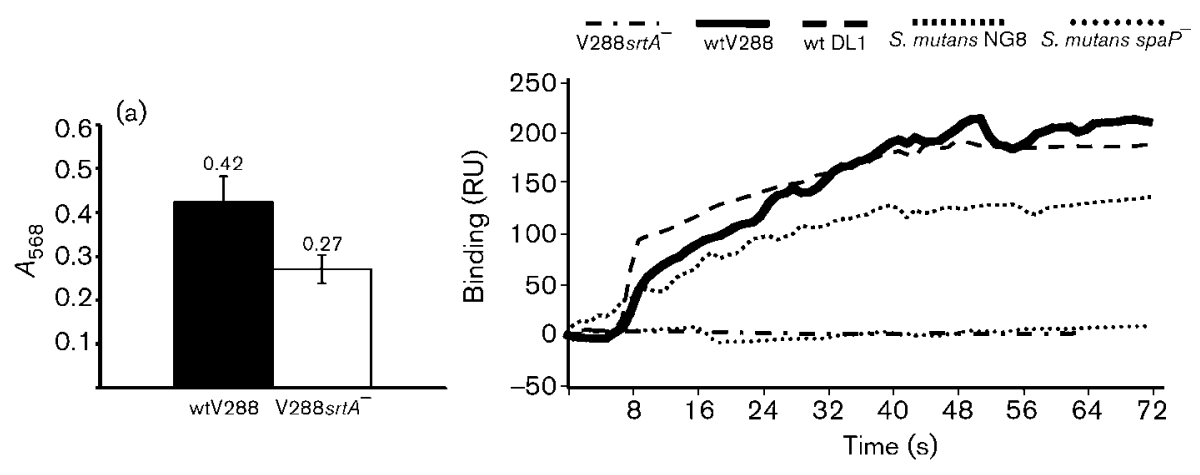

Fig. 1. Effects of $s r t A^{-}$mutation on S. gordonii V288 functions. (a) Biofilm-forming ability. Bacteria were grown in 96-well plates at $37{ }^{\circ} \mathrm{C}$ for $16-18 \mathrm{~h}$, and biofilm formation was assessed by crystal violet staining, as described in Methods. Data shown are means \pm SEM. (b) Binding of wtV288 and V288srt $A^{-}$mutant to salivary agglutinin. Salivary agglutinin was immobilized on an $\mathrm{F} 1$ sensor chip and the binding of bacterial cells was followed over time using BIAcore analysis. Cells $\left(1 \times 10^{7}\right.$ c.f.u. in

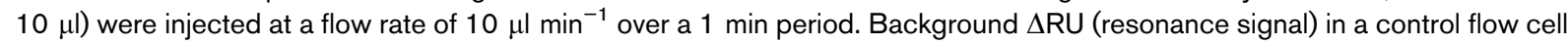
lacking agglutinin was subtracted from the experimental values. Binding of wtV288 (solid line) and V288srt $A^{-}$mutant (dashed line) cells is shown (in arbitrary resonance units, $\mathrm{Ru}$ ) in this representative surface plasmon resonance sensogram in comparison to the other strains tested.

\section{Structural effects}

Electron microscopy. To learn whether the $s r t A^{-}$ mutation influences cell-wall morphology, the wtV288 and V288srt $A^{-}$mutant strains were studied with brightfield microscopy, field emission scanning electron microscopy (FESEM) and transmission electron microscopy (TEM). The wild-type and the mutant strains showed similar ultrastructure (data not shown), but the V288srt $A^{-}$mutant showed fewer immunogold-labelled particles conjugated to anti-P1 reacting with SspA and SspB proteins than wtV288 (Fig. 2). The wtV288 strain bound $8.9 \pm 2.5($ mean $\pm \mathrm{SD})$ gold particles per cell; the V288st $A^{-}$mutant bound $2.8 \pm 1.7$ particles per cell. This difference was statistically significant $(P<0.05)$.

\section{Protein profiling}

The protein profiles of wtV288, wtDL1, V288srt ${ }^{-}$, $\mathrm{DL}_{1 s r t} A^{-}$and DL1srtA ${ }^{+}$were analysed by SDS-PAGE $(8 \%)$. Fractions were prepared from FMC culture supernatants (extracellular), mutanolysin digests containing cellwall materials, and residual cytoplasm. The wild-type and
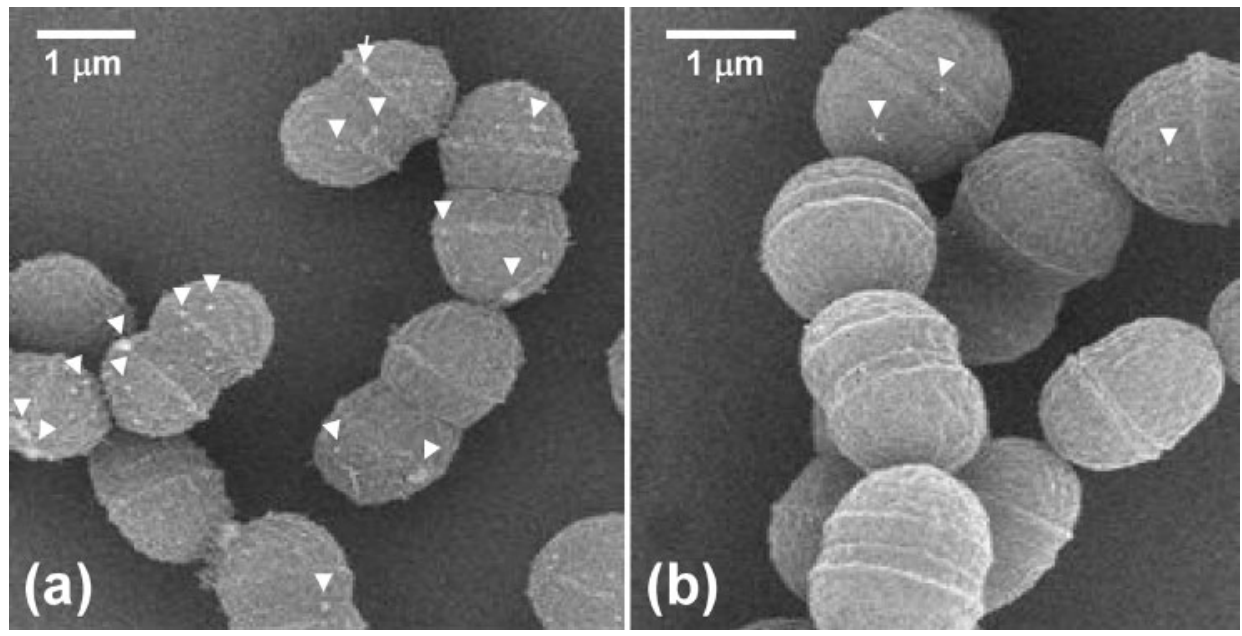

Fig. 2. Immunogold labelling and backscatter electron microscopy of the SspA and SspB antigens of wtV288 (a) and V288srt $A^{-}$mutant (b). Bacteria were grown overnight in $\mathrm{FMC}$ medium at $37{ }^{\circ} \mathrm{C}$, and subsequently stained with immunogoldlabelled rabbit anti-P1 antibodies for surface-expressed SspA/B, as described in Methods. Representative images are shown. 
(a)

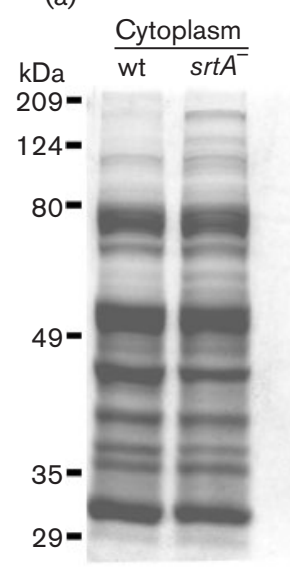

(c)

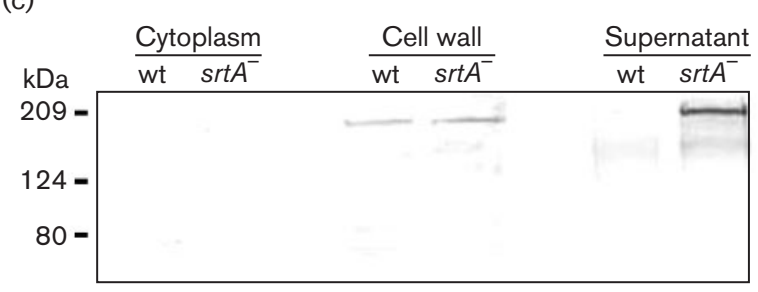

(b)

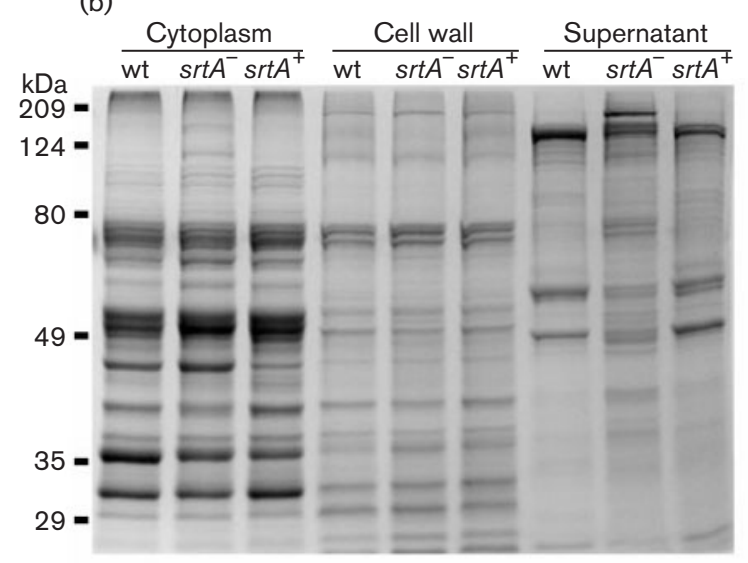

(d)

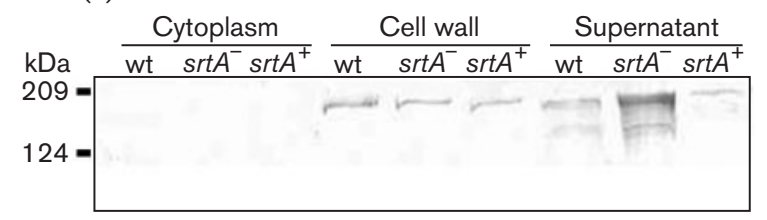

Fig. 3. Protein profiles of wild-type $S$. gordonii and $s r t A^{-}$mutants. Cytoplasmic, cell-wall and extracellular protein fractions were isolated by mutanolysin digest from wtV288 and V288srt $A^{-}(\mathrm{a}, \mathrm{c})$ or wtDL1, DL1srtA $A^{-}$and DL1srtA ${ }^{+}$(b, d). Proteins ( $20 \mu \mathrm{g}$ per lane) were separated by SDS-PAGE ( $8 \%)$ and visualized by staining with Coomassie blue (a, b). Alternatively, proteins were transferred to nitrocellulose membrane and the level of antigen I/II polypeptide detected by immunoblot analysis with polyclonal anti-P1 antibody (c, d). Molecular mass markers are indicated.

mutant strains generally showed similar but non-identical patterns of proteins (Fig. 3a, b). In all strains, lower molecular mass proteins were over-represented in the cytoplasmic and cell-wall fractions when compared to the supernatant fractions. Higher molecular mass proteins were over-represented in the supernatant fractions of ${\mathrm{V} 288 s r t A^{-}}^{-}$and DL1srtA $A^{-}$when compared to the wildtype strains. Complementation of $\operatorname{srtA}\left(\mathrm{DL} 1 s r t A^{+}\right)$ restored the wild-type phenotype protein profile (Fig. 3b).

To learn if the $s r t A$ mutation altered the routeing of SspA and $\mathrm{SspB}$ to the cell wall, the protein fractions were transferred to a nitrocellulose membrane, which was incubated with rabbit anti-P1 antibody (Fig. 3c, d). AntiP1 antibody reacted with a cell-wall antigen in the wildtype strains, the $s r t A^{-}$mutants and the DL1srt $A^{+}$strain. The antigen was not detected in the cytoplasm of any of the strains. P1 antigen was prominent in the supernatant of the deletion mutants (V288srt $A^{-}, \mathrm{DL}_{1} \mathrm{srt} A^{-}$) when compared to the wild-types or $\mathrm{DL} 1 s r t A^{+}$strains, suggesting abundant release of $\mathrm{SspA}$ and $\mathrm{SspB}$ into the supernatant during growth. The wtDL1 and complemented DL1srtA ${ }^{+}$showed a similar distribution of P1 antigen.

To clarify the seeming inconsistency in expression of cellsurface P1 antigen by the $s r t A^{-}$mutant and wild-type, as observed by electron microscopy and Western immunoblotting, a whole-cell ELISA experiment was carried out. When analysed by whole-cell ELISA, the $s r t A^{-}$mutants expressed less cell-surface P1 antigen than the wild-types. Complemented mutant DL1srt ${ }^{+}$expressed the same level of surface P1 antigen as the wild-type DL1 (Fig. 4).

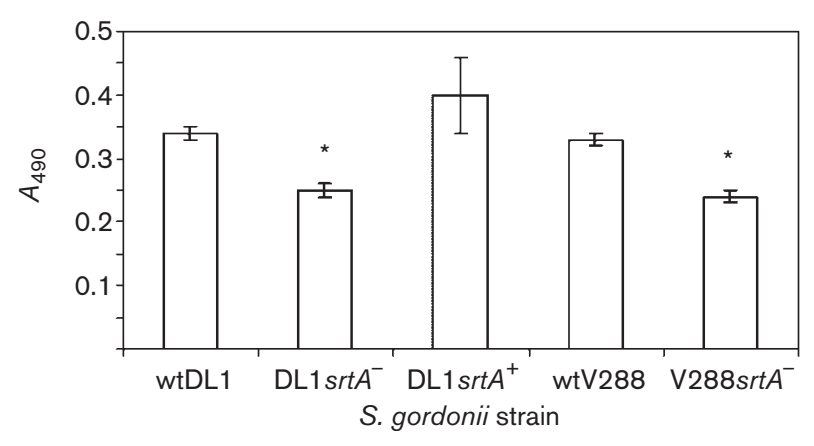

Fig. 4. Expression of cell-surface SspA/B adhesins of S. gordonii strains. Surface expression of antigen I/II polypeptides was estimated using a whole-cell ELISA as described in Methods. ${ }^{*}, P<0.001 ;$ mean $\pm \mathrm{SD}, n=6$. 


\section{Gene expression}

Since the $s r t A^{-}$deletion mutants showed an abundance of antigen I/II proteins in the supernatant compared to wildtype, bacteria might be upregulating expression of these adhesins in response to the srtA mutation.

We therefore studied the possibility that sortase A might be a general regulator of adhesin gene expression. Using realtime PCR, expression of specific mRNA for the LPXTGbearing adhesin proteins $\mathrm{SspA} / \mathrm{B}, \mathrm{Csh} \mathrm{A} / \mathrm{B}$ and $\mathrm{Hsa}$, and the non-LPXTG adhesins AbpA/B, FbpA and ScaA, were compared in wtV288 and ${\mathrm{V} 288 s r t A^{-}}^{-}$(Table 3a) and wtDL1, DL1 $s r t A^{-}$and DL1srtA ${ }^{+}$(Table 3b). Expression of $\operatorname{ssp} A / B, \quad \operatorname{sh} A / B, \quad a b p A / B$ and $f b p A$ were significantly upregulated in V288srtA ${ }^{-}$relative to wtV288 (Table 3a). Expression of scaA and hsa was similar in wtV288 and

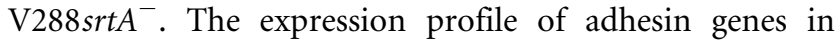
wtDL1 and DL1srtA ${ }^{-}$(Table 3b) was similar but not identical to wtV288 and V288srtA ${ }^{-}$. When compared to wtDL1, DL1 srt $A^{-}$genes $s s p A, c s h A / B, a b p A / B$, hs $a$ and $f b p A$ were all upregulated, although the typical fold-change was less than in the V288 background. Interestingly, scaA was also upregulated 3.2-fold in DL1 srtA $A^{-}$. Confirming that srtA regulated expression of the adhesin genes, DL1srt ${ }^{+}$ and wtDL1 showed similar levels of expression of adhesin genes (Table 3b).

\section{DISCUSSION}

The LPXTG family of surface proteins is essential for $S$. gordonii adhesion and colonization of the oral cavity, and can be modelled by SspA/B (El-Sabaeny et al., 2000; Holmes et al., 1998; Williams et al., 1994). The tandem sspA and sspB genes (Demuth et al., 1996) possess individual promoters that are differentially regulated in response to environmental conditions (El-Sabaeny et al., 2000). We hypothesized that functional presentation of $\mathrm{SspA} / \mathrm{B}$, the protein products of $s s p A$ and $s s p B$ genes, requires accessory genes such as srtA. Disruption of the srtA gene has now been shown to change the destination and functions of the SspA/B adhesins, consistent with our hypothesis. Furthermore, sortase A functions more globally in the regulation of adhesin gene expression, apparently optimizing adhesion function in challenging environments and conditions.

Consistent with loss of function of surface adhesins, the sortase A-deficient mutant showed decreased adhesion to immobilized salivary agglutinin, and reduced biofilmforming ability in vitro. Among these adhesins, SspA and SspB from the $s r t A^{-}$mutants appeared to be overrepresented in the extracellular milieu, while still expressed on the cell surface in reduced amounts, as shown by immunoelectron microscopy (Fig. 2) and whole-cell ELISA (Fig. 4). The reduction in cell-surface P1 antigen is consistent with the loss of sortase function. On the other hand, $\mathrm{P} 1$ antigen appeared to be overexpressed in the $s r t A^{-}$ mutants (Table 3), perhaps accumulating in the interior layers of the cell wall. This speculation is consistent with the observation that total wall-associated SspA and SspB were similar in the wild-type and $s r t A^{-}$mutants when cellwall fractions were analysed by Western immunoblotting (Fig. 3c, d). These data are consistent with the observations reported previously (Mazmanian et al., 2000), indicating that $s r t A^{-}$mutants of Staphylococcus aureus accumulate non-functional surface protein precursors in their cell wall. Loss of sortase function in the $s r t A^{-}$mutants, therefore, causes improper routeing of the adhesins through the wall.

In the $s r t A^{-}$mutants, LPXTG-containing proteins are synthesized and exported across the plasma membrane into the medium since they cannot bind peptidoglycan in the cell wall. In the absence of sortase A, cell-surface SspA/B is detectable, but less available to bind specific anti-P1 antibodies than on the wild-type strain. Furthermore, the SspA/B expressed on the $s r t A^{-}$mutant cell surface appears non-functional, since V288srt $A^{-}$, like the prototype $S$. mutans PC3370 spaP $P^{-}$mutant (Oli et al., 2006), was unable to bind its preferred (but not exclusive) salivary receptor, high molecular mass agglutinin. Hence, sortase A is required for functional presentation of SspA/B and likely other LPXTG adhesins on the cell surface of S. gordonii. In most cases, loss of function could be attributed specifically

Table 3. Relative levels of adhesin-specific RNA in S. gordonii srtA deletion and complementation mutants compared to parent strains V288 (a) or DL1 (b)

Values given represent mean $\pm \mathrm{SD}$ of three independent experiments performed in triplicate.

\begin{tabular}{|c|c|c|c|c|c|c|c|c|c|}
\hline & \multicolumn{9}{|c|}{ Fold change in gene expression } \\
\hline & $\operatorname{ssp} A$ & $s s p B$ & $\operatorname{csh} A$ & $\operatorname{csh} B$ & $a b p A$ & $a b p B$ & hsa & scaA & $f b p A$ \\
\hline & \multicolumn{9}{|c|}{ (a) Change relative to $w t V 288$} \\
\hline \multirow[t]{2}{*}{ V288srt $A^{-}$} & $3.8 \pm 0.27^{\star}$ & $2.4 \pm 0.13^{*}$ & $6.3 \pm 0.70^{*}$ & $1.9 \pm 0.08^{*}$ & $2.7 \pm 0.71^{\star}$ & $13.0 \pm 1.41^{\star}$ & $1.3 \pm 0.28$ & $1.0 \pm 0.14$ & $5.7 \pm 0.47^{\star}$ \\
\hline & \multicolumn{9}{|c|}{ (b) Change relative to wtDL1 } \\
\hline DL1srtA $A^{-}$ & $2.4 \pm 0.64^{*}$ & $2.2 \pm 0.92$ & $1.6 \pm 0.07^{\star}$ & $3.9 \pm 0.49^{*}$ & $2.1 \pm 0.28^{\star}$ & $2.7 \pm 0.64^{\star}$ & $2.3 \pm 0.35^{\star}$ & $3.2 \pm 0.01^{\star}$ & $3.7 \pm 1.06^{*}$ \\
\hline DL1srtA $A^{+}$ & $1.0 \pm 0.07$ & $1.0 \pm 0.28$ & $0.8 \pm 0.14$ & $0.8 \pm 0.07$ & $1.3 \pm 0.07$ & $0.9 \pm 0.01$ & $0.6 \pm 0.07$ & $0.9 \pm 0.01$ & $0.8 \pm 0.07$ \\
\hline
\end{tabular}

${ }^{\star} P<0.05$. 
to $s r t A$ since DL1srtA ${ }^{+}$, which complemented the $s r t A^{-}$ mutation, showed complete rescue of adhesin gene expression at the transcriptional level, and was indistinguishable from the wild-type strain. Furthermore, a restoration of adhesion function has been specifically demonstrated for DL1srtA ${ }^{+}$(Nobbs et al., 2007).

While the $s r t A^{-}$mutation affected adhesin-related functions and functional expression of SspA/B, cell morphology was not remarkably altered. The V288srtA ${ }^{-}$and wtV288 cells showed similar bright-field and ultrastructural morphology (data not shown). Furthermore, free-growing V288srtA $A^{-}$and wtV288 cells (and wtDL1, DL1 srtA $A^{-}$and DL1 $s r t A^{+}$) grew similarly in suspension culture (data not shown). Loss of sortase A activity was, however, associated with a reduction in biofilm formation. During growth of $s r t A^{-}$mutants, our data indicated that SspA and SspB and other LPXTG adhesins may be inappropriately presented on the cell wall and also overexpressed and exported. Soluble adhesins are likely to competitively inhibit cell binding by inappropriately expressed adhesins that are present on the cell wall. Consequently, cells prepared for electron microscopy and salivary agglutinin adhesion assays were washed in advance to remove extracellular proteins, including released SspA and SspB in the culture media. Yet, the presence of poorly functional LPXTG adhesins and soluble exported LPXTG adhesins released by growing cells remained throughout the in vitro biofilm formation assays. Given that adhesion and biofilm formation are adhesin-dependent and that LPXTG adhesins predominate, a sortase A deficiency might, therefore, have been expected to result in greater loss of function than the $36 \%$ reduction observed for ${\mathrm{V} 288 s r t A^{-}}^{-}$relative to $w t V 288$. These observations implied the existence of a compensatory mechanism(s) to maintain at least some level of adhesion.

The data presented here clearly demonstrate that the $s r t A$ mutation was accompanied by compensatory changes in adhesin gene expression. Deletion of $s r t A$ caused a strainspecific upregulation in adhesin gene mRNAs ( $a b p A / B$; LPXTG adhesins $s s p A / B, c s h A / B, h s a)$. Furthermore, these changes were restored upon complementation of srtA mutation. In V288srtA ${ }^{-}$, the magnitude of increase in expression of LPXTG-adhesin genes was greater than in DL1 $s r t A^{-}$, but in DL1srtA ${ }^{-}, s c a A$, a non-LPXTG-adhesive protein, was substantially upregulated. Hence, S. gordonii cells recognized the loss of $s r t A$, or inappropriate processing, presentation or routeing of LPXTG adhesins, and responded. Several $S$. gordonii adhesins are known to contribute to transcriptional regulation of alternative adhesins. For example, deletion of $s s p A / B$ increases $s c a A$ expression at the gene and protein levels (Zhang et al., 2005), HppA and FbpA appear to regulate expression of CshA (McNab \& Jenkinson, 1998), while SspB is regulated by SspA (El-Sabaeny et al., 2001). Thus, one might speculate that those adhesin proteins affected by the sortase A mutation subsequently functioned in transcriptional regulation of alternative compensatory adhesins.
While this finding is consistent with a role for sortase A in a regulated network of proteins and genes involved in adhesin-related functions, it remains to be determined how adhesin expression is transcriptionally regulated, although such studies are currently under way. Extensive changes in gene expression are required for $S$. gordonii to achieve a biofilm state (Gilmore et al., 2003; Zhang et al., 2005), including genes encoding adhesins and transcriptional regulators. Its role as a gene regulator may, therefore, provide a further explanation as to the importance of sortase A in enabling biofilm formation.

Collectively, these data strongly suggest that the adhesins of S. gordonii contribute to the transcriptional control of an array of adhesin genes that form an adhesin maintenance system (AMS). Furthermore, these adhesin protein domains function independently, with no one adhesin solely responsible for adhesion of a streptococcal cell to a specific biological substrate (Gong \& Herzberg, 1997). By modulating the expression of these genes, sortase A serves as an additional component of this AMS. Thus, upon improper presentation of adhesins, as occurs upon loss of $s r t A$, the AMS appears to enable the cell wall to remodel its specificity. The cell-wall array of adhesins can be viewed as 'plastic' and accommodating to abnormal adhesion. We posit, therefore, that the AMS provides compensatory failsafe mechanisms that this commensal species needs to persist within the host in the face of constantly changing environmental conditions, and that sortase A forms an essential part of this mechanism.

\section{ACKNOWLEDGEMENTS}

We thank Karen Ross, Brian Monk (University of Otago, NZ), Yasuhito Yamamoto and Todd Markowski for helpful suggestions. The authors dedicate this work to their wonderful collaborator, Stanley L. Erlandsen, who passed away suddenly on December 5, 2005. This work was supported by NIH/NIDCR grants R01DE08590, DE008007 and DE013882. J. R. J. was supported by a summer research fellowship from the NIH/NIDCR-supported MinnCResT program grant T32DE007288.

\section{REFERENCES}

Bolken, T. C., Franke, C. A., Jones, K. F., Zeller, G. O., Jones, C. H., Dutton, E. K. \& Hruby, D. E. (2001). Inactivation of the srtA gene in Streptococcus gordonii inhibits cell wall anchoring of surface proteins and decreases in vitro and in vivo adhesion. Infect Immun 69, 75-80.

Brady, L. J., Piacentini, D. A., Crowley, P. J., Oyston, P. C. \& Bleiweis, A. S. (1992). Differentiation of salivary agglutinin-mediated adherence and aggregation of mutans streptococci by use of monoclonal antibodies against the major surface adhesin P1. Infect Immun 60, 1008-1017.

Brady, L. J., Cvitkovitch, D. G., Geric, C. M., Addison, M. N., Joyce, J. C., Crowley, P. J. \& Bleiweis, A. S. (1998). Deletion of the central proline-rich repeat domain results in altered antigenicity and lack of surface expression of the Streptococcus mutans P1 adhesin molecule. Infect Immun 66, 4274-4282. 
Clark, W. B., Bammann, L. L. \& Gibbons, R. J. (1978). Comparative estimates of bacterial affinities and adsorption sites on hydroxyapatite surfaces. Infect Immun 19, 846-853.

Demuth, D. R. \& Irvine, D. C. (2002). Structural and functional variation within the alanine-rich repetitive domain of streptococcal antigen I/II. Infect Immun 70, 6389-6398.

Demuth, D. R., Duan, Y., Brooks, W., Holmes, A. R., McNab, R. \& Jenkinson, H. F. (1996). Tandem genes encode cell-surface polypeptides SspA and SspB which mediate adhesion of the oral bacterium Streptococcus gordonii to human and bacterial receptors. Mol Microbiol 20, 403-413.

Demuth, D. R., Duan, Y., Jenkinson, H. F., McNab, R., Gil, S. \& Lamont, R. J. (1997). Interruption of the Streptococcus gordonii M5 sspA/sspB intergenic region by an insertion sequence related to IS1167 of Streptococcus pneumoniae. Microbiology 143, 2047-2055.

Douglas, C. W., Heath, J., Hampton, K. K. \& Preston, F. E. (1993). Identity of viridans streptococci isolated from cases of infective endocarditis. J Med Microbiol 39, 179-182.

Dunny, G. M., Lee, L. N. \& LeBlanc, D. J. (1991). Improved electroporation and cloning vector system for gram-positive bacteria. Appl Environ Microbiol 57, 1194-1201.

El-Sabaeny, A., Demuth, D. R., Park, Y. \& Lamont, R. J. (2000). Environmental conditions modulate the expression of the sspA and sspB genes in Streptococcus gordonii. Microb Pathog 29, 101-113.

El-Sabaeny, A., Demuth, D. R. \& Lamont, R. J. (2001). Regulation of Streptococcus gordonii ssp $B$ by the sspA gene product. Infect Immun 69, $6520-6522$.

Fischetti, V. A., Pancholi, V. \& Schneewind, O. (1990). Conservation of a hexapeptide sequence in the anchor region of surface proteins from gram-positive cocci. Mol Microbiol 4, 1603-1605.

Forester, H., Hunter, N. \& Knox, K. W. (1983). Characteristics of a high molecular weight extracellular protein of Streptococcus mutans. J Gen Microbiol 129, 2779-2788.

Gilmore, K. S., Srinivas, P., Akins, D. R., Hatter, K. L. \& Gilmore, M. S. (2003). Growth, development and gene expression in a persistent Streptococcus gordonii biofilm. Infect Immun 71, 4759-4766.

Gong, K. \& Herzberg, M. C. (1997). Streptococcus sanguis expresses a 150-kilodalton two-domain adhesin: characterization of several independent adhesin epitopes. Infect Immun 65, 3815-3821.

Heddle, C., Nobbs, A. H., Jakubovics, N. S., Gal, M., Mansell, J. P., Dymock, D. \& Jenkinson, H. F. (2003). Host collagen signal induces antigen I/II adhesin and invasin gene expression in oral Streptococcus gordonii. Mol Microbiol 50, 597-607.

Herzberg, M. C., Erickson, P. R., Kane, P. K., Clawson, D. J., Clawson, C. C. \& Hoff, F. A. (1990). Platelet-interactive products of Streptococcus sanguis protoplasts. Infect Immun 58, 4117-4125.

Holmes, A. R., Gopal, P. K. \& Jenkinson, H. F. (1995). Adherence of Candida albicans to a cell surface polysaccharide receptor on Streptococcus gordonii. Infect Immun 63, 1827-1834.

Holmes, A. R., Gilbert, C., Wells, J. M. \& Jenkinson, H. F. (1998). Binding properties of Streptococcus gordonii SspA and SspB (antigen I/ II family) polypeptides expressed on the cell surface of Lactococcus lactis MG1363. Infect Immun 66, 4633-4639.

Jakubovics, N. S., Kerrigan, S. W., Nobbs, A. H., Stromberg, N., van Dolleweerd, C. J., Cox, D. M., Kelly, C. G. \& Jenkinson, H. F. (2005). Functions of cell surface-anchored antigen I/II family and Hsa polypeptides in interactions of Streptococcus gordonii with host receptors. Infect Immun 73, 6629-6638.

Kuboniwa, M., Tribble, G. D., James, C. E., Kilic, A. O., Tao, L., Herzberg, M. C., Shizukuishi, S. \& Lamont, R. J. (2006). Streptococcus gordonii utilizes several distinct gene functions to recruit
Porphyromonas gingivalis into a mixed community. Mol Microbiol 60, 121-139.

Lee, S. F. \& Boran, T. L. (2003). Roles of sortase in surface expression of the major protein adhesin P1, saliva-induced aggregation and adherence, and cariogenicity of Streptococcus mutans. Infect Immun 71, 676-681.

Levesque, C. M., Voronejskaia, E., Huang, Y. C., Mair, R. W., Ellen, R. P. \& Cvitkovitch, D. G. (2005). Involvement of sortase anchoring of cell wall proteins in biofilm formation by Streptococcus mutans. Infect Immun 73, 3773-3777.

Loo, C. Y., Corliss, D. A. \& Ganeshkumar, N. (2000). Streptococcus gordonii biofilm formation: identification of genes that code for biofilm phenotypes. J Bacteriol 182, 1374-1382.

Macrina, F. L., Evans, R. P., Tobian, J. A., Hartley, D. L., Clewell, D. B. \& Jones, K. R. (1983). Novel shuttle plasmid vehicles for EscherichiaStreptococcus transgeneric cloning. Gene 25, 145-150.

Mazmanian, S. K., Liu, G., Ton-That, H. \& Schneewind, O. (1999). Staphylococcus aureus sortase, an enzyme that anchors surface proteins to the cell wall. Science 285, 760-763.

Mazmanian, S. K., Liu, G., Jensen, E. R., Lenoy, E. \& Schneewind, O. (2000). Staphylococcus aureus sortase mutants defective in the display of surface proteins and in the pathogenesis of animal infections. Proc Natl Acad Sci U S A 97, 5510-5515.

Mazmanian, S. K., Ton-That, H., Su, K. \& Schneewind, O. (2002). An iron-regulated sortase anchors a class of surface protein during Staphylococcus aureus pathogenesis. Proc Natl Acad Sci U S A 99, 2293-2298.

McNab, R. \& Jenkinson, H. F. (1998). Altered adherence properties of a Streptococcus gordonii $h p p A$ (oligopeptide permease) mutant result from transcriptional effects on cshA adhesin gene expression. Microbiology 144, 127-136.

Nobbs, A. H., Zhang, Y., Khammanivong, A. \& Herzberg, M. C. (2007). Streptococcus gordonii Hsa environmentally constrains competitive binding by Streptococcus sanguinis to saliva-coated hydroxyapatite. J Bacteriol 189, 3106-3114.

Oli, M. W., McArthur, W. P. \& Brady, L. J. (2006). A whole cell BIAcore assay to evaluate P1-mediated adherence of Streptococcus mutans to human salivary agglutinin and inhibition by specific antibodies. J Microbiol Methods 65, 503-511.

Olmsted, S. B., Erlandsen, S. L., Dunny, G. M. \& Wells, C. L. (1993). High-resolution visualization by field emission scanning electron microscopy of Enterococcus faecalis surface proteins encoded by the pheromone-inducible conjugative plasmid pCF10. J Bacteriol 175, 6229-6237.

Pakula, R. \& Walczak, W. (1963). On the nature of competence of transformable streptococci. J Gen Microbiol 31, 125-133.

Paterson, G. K. \& Mitchell, T. J. (2004). The biology of Gram-positive sortase enzymes. Trends Microbiol 12, 89-95.

Rundegren, J. \& Arnold, R. R. (1987). Differentiation and interaction of secretory immunoglobulin A and a calcium-dependent parotid agglutinin for several bacterial strains. Infect Immun 55, 288-292.

Sambrook, J., Fritsch, E. F. \& Maniatis, T. (1989). Molecular Cloning: a Laboratory Manual, 2nd edn. Cold Spring Harbor, NY: Cold Spring Harbor Laboratory.

Schachtele, C. F., Nobbs, A. H., Zhang, Y., Costalonga, M. \& Herzberg, M. C. (2007). Oral streptococci: commensals and opportunistic pathogens. In Molecular Biology of Streptococci, pp. 411-462. Edited by R. H. S. Chhatwal. Norfolk, UK: Horizon Bioscience.

Schneewind, O., Model, P. \& Fischetti, V. A. (1992). Sorting of protein A to the staphylococcal cell wall. Cell 70, 267-281. 
Schneewind, O., Mihaylova-Petkov, D. \& Model, P. (1993). Cell wall sorting signals in surface proteins of gram-positive bacteria. EMBO J 12, 4803-4811.

Scott, C. J., McDowell, A., Martin, S. L., Lynas, J. F., Vandenbroeck, K. \& Walker, B. (2002). Irreversible inhibition of the bacterial cysteine protease-transpeptidase sortase (SrtA) by substrate-derived affinity labels. Biochem J 366, 953-958.

Sommer, P., Gleyzal, C., Guerret, S., Etienne, J. \& Grimaud, J. A. (1992). Induction of a putative laminin-binding protein of Streptococcus gordonii in human infective endocarditis. Infect Immun 60, 360-365.

Terleckyj, B., Willett, N. P. \& Shockman, G. D. (1975). Growth of several cariogenic strains of oral streptococci in a chemically defined medium. Infect Immun 11, 649-655.
Williams, M. D., Ouyang, T. X. \& Flickinger, M. C. (1994). Starvationinduced expression of SspA and SspB: the effects of a null mutation in sspA on Escherichia coli protein synthesis and survival during growth and prolonged starvation. Mol Microbiol 11, 1029-1043.

Zhang, Y., Lei, Y., Khammanivong, A. \& Herzberg, M. C. (2004). Identification of a novel two-component system in Streptococcus gordonii V288 involved in biofilm formation. Infect Immun 72, 3489-3494.

Zhang, Y., Lei, Y., Nobbs, A., Khammanivong, A. \& Herzberg, M. C. (2005). Inactivation of Streptococcus gordonii SspAB alters expression of multiple adhesin genes. Infect Immun 73, 3351-3357.

Edited by: P. E. Kolenbrander 